\title{
Possibilidades de melhorias ambientais no processo de reciclagem do polietileno
}

\section{Possibilities for environmental improvements in the polyethylene recycling process}

\author{
Elaine Aparecida da Silva ${ }^{1 *}$ e José Machado Moita Neto² \\ 'Departamento de Recursos Hídricos, Geotecnia e Saneamento Ambiental, \\ Universidade Federal do Piauí - UFPI, Teresina, PI, Brasil \\ ${ }^{2}$ Departamento de Química, Universidade Federal do Piauí - UFPI, Teresina, PI, Brasil \\ *elaine@ufpi.edu.br
}

\begin{abstract}
Resumo
A reciclagem mecânica é uma das possibilidades existentes para revalorização dos resíduos plásticos. Neste trabalho, foram acompanhadas as atividades de uma indústria, localizada em Teresina-PI, que realiza a reciclagem mecânica de polietileno (PEBD e PEAD) para a produção de sacolas. A qualidade da matéria-prima pós-uso influencia a qualidade do produto final e determina etapas adicionais em relação ao processamento da resina virgem, como lavagem, secagem e extrusão para produção de grãos. O efluente gerado na etapa de pré-tratamento dos reciclados, o consumo de energia e recursos humanos envolvidos impactam os aspectos ambientais, econômicos e sociais do processo. A reciclagem mecânica só pode ser considerada vantajosa se for dada uma destinação ou disposição final ambientalmente correta do que não é aproveitado na indústria; incorporada a externalidade econômica de realizar tratamento do efluente gerado, e, por fim, qualificar e remunerar de modo justo o catador que disponibiliza a matéria-prima para a indústria.
\end{abstract}

Palavras-chave: gestão ambiental, reciclagem mecânica, polietileno.

\begin{abstract}
Mechanical recycling is one alternative for the revaluation of plastic waste. In this study, the activities of a factory in Teresina-PI, which mechanically recycles polyethylene (LDPE and HDPE) to produce plastic bags were analysed. The quality of the raw material after use influences the quality of the final product and determines the need for additional processing stages when compared with the virgin resin, such as washing, drying and extrusion for grain production. The effluent generated by the pretreatment of the recycled goods, the energy consumption and the human resources involved have an impact on the environmental, economical and social aspects of the process. Mechanical recycling can only be considered advantageous if: what is not used by the factory is correctly disposed of; if the economic externality to treat the effluent generated is incorporated to the recycling process and when it qualifies and remunerates fairly the individual who collects the raw material for the factory.
\end{abstract}

Keywords: environmental management, mechanical recycling, polyethylene.

\section{Introdução}

A reciclagem é definida pelo Instituto Brasileiro de Geografia e Estatística (IBGE) como o

[...] conjunto de atividades e práticas pelos quais os resíduos são coletados, separados e submetidos ao processo de transformação para serem utilizados como matérias-primas na manufatura de bens.

Ela é um dos indicadores de desenvolvimento sustentável da dimensão econômica e é apontada como uma atividade-chave para solucionar o problema da destinação inadequada dos resíduos sólidos ${ }^{[1]}$.

O conceito de reciclagem expresso na Política Nacional dos Resíduos Sólidos (PNRS) é mais completo, pois pontua que para a transformação dos resíduos devem ser analisadas as condições e os padrões estabelecidos pelos órgãos competentes do Sistema Nacional do Meio Ambiente (Sisnama) e, se couber, do Sistema Nacional de Vigilância Sanitária (SNVS) e do Sistema Único de Atenção à Sanidade Agropecuária (Suasa) ${ }^{[2]}$.

A PNRS estabelece que somente os materiais que não tem possibilidade de recuperação e tratamento (rejeitos) sejam encaminhados para aterros sanitários. Logo, os resíduos sólidos com alguma possibilidade de reaproveitamento e/ou reciclagem deverão ter destino ambientalmente correto, socialmente justo e economicamente viável. 
Quadro 1. Características e aplicações do PEAD, PEBD e PELBD.

\begin{tabular}{|l|l|}
\hline Polietilenos & \multicolumn{1}{c|}{ Características e aplicações } \\
\hline PEAD & $\begin{array}{l}\text { Resistente a baixas temperaturas, leve, impermeável, rígido e com resistência química e mecânica. Pode ser usado na fabricação de } \\
\text { tampas de refrigerante, brinquedos, eletrodomésticos, caixas plásticas, sacarias (revestimento e impermeabilização), entre outros. }\end{array}$ \\
\hline PEBD & $\begin{array}{l}\text { Flexível, leve e transparente. Pode ser utilizado na produção de filmes termoencolhíveis ou termocontráteis, como fios e cabos para } \\
\text { televisão e telefone, filmes de uso geral, mangueiras, camada selante em estruturas cartonadas (embalagens longa vida), entre outros. }\end{array}$ \\
\hline PELBD & $\begin{array}{l}\text { Flexível, leve e transparente. Pode ser aplicado, principalmente, na produção de embalagens de alimentos, fraldas, absorventes } \\
\text { higiênicos e na sacaria industrial. }\end{array}$ \\
\hline
\end{tabular}

Fonte: CETESB e SINDPLAST ${ }^{[3]}$.

Na PNRS, a prioridade na gestão dos resíduos sólidos é a não-geração ( $\operatorname{artigo} 9^{\circ}$ da Lei no $\left.12.305 / 2010\right)^{[2]}$. A importância dos plásticos para a sociedade atual não permite vislumbrar a abolição do seu uso. Além disso, para algumas de suas aplicações em saneamento e saúde, por exemplo, ainda não foram encontrados substitutos melhores, nem mesmo ambientalmente.

No caso dos resíduos plásticos, dentre as possibilidades disponíveis, está a reciclagem secundária ou mecânica que "[...] consiste na conversão dos descartes plásticos em grânulos que podem ser reutilizados pelo setor produtivo na confecção de outros produtos $[\ldots]^{\text {"’[3] }}$.

Em geral, avalia-se que o uso de material reciclado traz mais respeito ao ambiente, pois não há retirada de nova matéria-prima da natureza e os resíduos "aproveitáveis" não serão encaminhados para disposição final em aterro. No entanto, outros fatores como: despreparo técnico na área de polímeros e a não separação do resíduo na fonte geradora podem levar ao comprometimento da reciclagem dos plásticos como alternativa adequada.

Os tipos de polímeros mais consumidos (considerados commodities) são os polietilenos, polipropilenos, poli (cloreto de vinila), poliestirenos, poliésteres e poliuretanos ${ }^{[3,4]}$. O polietileno $(\mathrm{PE})$ pode ser de diferentes tipos, conforme as condições reacionais e o sistema catalítico empregado na polimerização: polietileno de baixa densidade (PEBD), polietileno de alta densidade (PEAD), polietileno linear de baixa densidade (PELBD), polietileno de ultra alto peso molecular (PEUAPM) e polietileno de ultra baixa densidade $(\mathrm{PEUBD})^{[5]}$. As principais características e aplicações do PEAD, PEBD e PELBD podem ser observadas no Quadro 1.

Grande parte dos plásticos transformados pela indústria é destinada ao setor de embalagens, que por terem baixo tempo de ciclo de vida e, portanto, grande descartabilidade, logo se transformam em resíduos sólidos.

Neste trabalho, são apresentadas as atividades desenvolvidas em uma indústria de reciclagem mecânica de plásticos com o objetivo de avaliar até que ponto a reciclagem é vantajosa do ponto de vista ambiental. Também, são identificadas/discutidas possibilidades para a atividade tornar-se socialmente mais justa mantendo sua viabilidade econômica.

A indústria visitada desenvolve o processo de reciclagem mecânica de plásticos típico, a exemplo dos casos citados por Spinacé e Paoli ${ }^{[6]}$, Bordonalli e Mendes ${ }^{[7]}$, Faria e Pacheco ${ }^{[8,9]}$ e Pacheco et al. ${ }^{[10]}$. Contudo, o caso ora apresentado pode não ilustrar a complexidade envolvida no desenvolvimento desse processo industrial em outros contextos.

\section{Metodologia}

Foram realizadas nove visitas à indústria e acompanhadas todas as suas atividades: aquisição de matéria-prima, processo produtivo (segregação, lavagem, extrusão em grãos, extrusão filme e corte/solda) e tratamento dos efluentes resultantes da lavagem dos plásticos. Além disso, foi feito um inventário das máquinas com o objetivo de conhecer especificações como potência e o tempo de funcionamento de cada uma. A autorização para realizar a coleta de dados foi dada pelo gerente de produção da indústria após a explicação sobre a proposta do trabalho.

Foram coletados dados de consumo, produção e descarte mensal da indústria de reciclagem de plásticos. Algumas estimativas foram feitas baseadas na composição do produto final (sacola plástica reciclada) fornecida pelo gerente de produção. O processo produtivo é descrito para uma melhor compreensão dos fluxos de matéria e energia vinculados à produção de sacolas plásticas. Todas as características do processo industrial foram observadas durante as visitas.

\section{Resultados e Discussão}

Nesta seção é discutido como a indústria utiliza e descarta os recursos determinantes para que a atividade seja ou não considerada ambientalmente correta, socialmente justa e economicamente viável.

As atividades desenvolvidas na indústria de plásticos pesquisada são a produção de resinas recicladas e de embalagens flexíveis a partir de resina virgem e reciclada pelo processo de extrusão. Os resíduos são separados manualmente, sendo analisado na separação dos diferentes tipos de plásticos o aspecto visual e o som emitido quando é comprimido na mão (cristalinidade). Depois disso, o plástico selecionado é lavado, seco, moído e extrusado (ou extrudado). No setor de produção de embalagens, as resinas recicladas são, novamente, extrusadas e transformadas em filmes flexíveis e, posteriormente, em sacolas.

Os tipos e a proporção, em média, dos resíduos comprados para a produção de resinas recicladas são: PEBD (80\%), PEAD (8\%), 'Stretch'* (5\%), Polipropileno - PP (3\%), Papel/Papelão (3\%) e outros (1\%), que corresponde a fitas adesivas, materiais descartáveis e pequenos objetos. O objetivo é reciclar somente PEBD e PEAD. Os demais resíduos são adquiridos compulsoriamente. Como não há mercado para o 'stretch', é feito um aproveitamento interno em que ele é utilizado como carga para economizar PEBD.

\footnotetext{
* Stretch significa estirado/esticado é uma das variações do polietileno, resistente e com baixíssima espessura.
} 
O processo de produção de resina reciclada começou há mais de seis anos nessa indústria, mesmo assim não há cadastro de fornecedores e nem de compradores de resíduos pós-consumo que não tem possibilidade de utilização na própria indústria e poderia ser utilizado em outros processos industriais. Por isso, o PP está estocado há mais de cinco meses e, também, alguns resíduos são encaminhados para $o$ aterro da cidade

O PEBD e o PEAD pós-consumo são processados separadamente com o objetivo de obter uma resina reciclada o mais próximo possível da matéria-prima virgem. Além disso, essa separação é fundamental para que sejam adicionadas as quantidades corretas de cada tipo de polímero na fabricação da embalagem reciclada.

Na produção de $175 \mathrm{~kg}$ de filme plástico reciclado são utilizadas as seguintes proporções de matérias-primas: $85 \%$ de Polietileno de Baixa Densidade Reciclado (PEBDrec), $14 \%$ de Polietileno de Alta Densidade Reciclado (PEADrec), $0,5 \%$ de dessecante (composto de PVC) e $0,5 \%$ de pigmento. Neste processo são gerados $10 \mathrm{~kg}$ de aparas.

O consumo, produção e descarte mensal da indústria de reciclagem de plásticos estão transcritos na Tabela 1 . A quantidade de pigmento e dessecante foi estimada, baseada na composição do produto final (sacola plástica reciclada) fornecida pelo gerente de produção.

\section{1 Água}

Aágua utilizada na indústria de reciclagem de plásticos é captada de um poço que não possui outorga de uso. Por não haver controle do órgão licenciador sobre a quantidade apresada e nem dos parâmetros de lançamento da água servida, a indústria emprega esse recurso no processo industrial e na lavagem das suas máquinas sem qualquer política específica de uso deste importante recurso natural.

Essa situação influencia na oportunidade da indústria comprar matéria-prima adquirida do aterro (que é mais barata e possui uma oferta maior do que a segregada na fonte) e,

Tabela 1. Consumo, produção e descarte característicos da indústria de reciclagem de plásticos.

\begin{tabular}{ll}
\hline \multicolumn{1}{c}{ Descrição } & \multicolumn{1}{c}{ Quantidade mensal } \\
\hline PEBD e PEAD virgem & $7.350 \mathrm{~kg}$ \\
PEBD pós-consumo & $12.000 \mathrm{~kg}$ \\
PEAD pós-consumo & $8.000 \mathrm{~kg}$ \\
Pigmento & $240 \mathrm{~kg}$ (estimada) \\
Dessecante & $240 \mathrm{~kg}$ (estimada) \\
Floculante & $500 \mathrm{~L}$ \\
Desinfetante & $100 \mathrm{~L}$ \\
Grãos de PEBD & $40.044 \mathrm{~kg}$ \\
Grãos de PEAD & $2.055 \mathrm{~kg}$ \\
Filme reciclado (2 $\mu \mathrm{m}$ de espessura) & $88.791,52 \mathrm{~kg}$ \\
Aparas da extrusão em filme & $1.254,18 \mathrm{~kg}$ \\
Aparas de acabamento na sacoleira & $1.538,8 \mathrm{~kg}$ \\
Efluente (descartado) & Mínimo: $27.000 \mathrm{~L}$ \\
& Máximo: $50.000 \mathrm{~L}$ \\
Borra (descartada) & Mínimo: $2.300 \mathrm{~L}$ \\
& Máximo: $4.000 \mathrm{~L}$ \\
\hline
\end{tabular}

deste modo, impregnada de mais impurezas como poeira e gordura. O não atendimento à PNRS, que proíbe o envio de resíduos com potencial para reutilização e/ou reciclagem para aterros, agrava ainda mais esse quadro.

Mancini et al. ${ }^{[11]}$, constataram que, no mínimo, 30\% da massa atribuída aos filmes plásticos é constituída de impurezas líquidas e sólidas quando a fonte da matéria-prima é a coleta comum. Quando é a coleta seletiva, o teor máximo de impurezas obtido é pouco maior que $10 \%$. Considerando esse aspecto de segregação na fonte, infere-se que o plástico do aterro deve possuir uma proporção ainda maior do que $30 \%$ de impurezas em sua massa. Além de maior risco à saúde dos funcionários que selecionam o material.

São realizados três tipos de tratamento da água para fins de reuso no mesmo processo industrial: 1) físico - a) tanque de areia e seixo e b) peneira para plásticos; 2) físico-químico - floculação e 3) químico - desinfetante (cloro ou composto de cloro). Tal prática, associada à qualidade do plástico pós-consumo que tem como origem o aterro, tem influência direta na quantidade de ciclos de reutilização da água.

Outros problemas associados ao consumo da água utilizada na lavagem do plástico pós-consumo é a geração de efluentes e como a indústria realiza o seu descarte. Foi declarado que não é feito tratamento para posterior lançamento em corpo d'água, tampouco outorga para fins de lançamento de efluentes.

O descarte do efluente final e da borra gerada é terceirizado para uma empresa que realiza o seu recolhimento. A quantidade de efluente descartado é de 80.000 L a 100.000 L, no período de dois a três meses, que corresponde à quantidade de água que circula na máquina de limpeza e na estação de tratamento. Não foi informado o seu destino. A partir dessa informação, pode-se inferir que são utilizados cerca de $1200 \mathrm{~L} /$ dia ou $36000 \mathrm{~L} / \mathrm{mês}$. A quantidade de borra retirada é de $7.000 \mathrm{~L}$ a $8.000 \mathrm{~L}$, no mesmo período, e a disposição final desse material é o aterro controlado da cidade.

A Lei Municipal n ${ }^{\circ} 4.413$, de 18 de junho de 2013, que dispõe sobre os serviços e obras para a coleta, tratamento e disposição final dos esgotos sanitários dos estabelecimentos industriais de Teresina, proíbe essa prática e indica as penalidades que podem ser aplicadas de forma gradativa: notificação, multa e suspensão de alvará de funcionamento ${ }^{[12]}$.

O artigo 13 da referida Lei é aplicável ao caso da indústria visitada: "As edificações já existentes desprovidas de adequadas instalações deverão ser adaptadas ao que dispõe esta lei, no prazo máximo de doze meses". A multa, para o caso de não atendimento é R \$3.000,00 para pequenas empresas e $\mathrm{R} \$ 5.000,00$ para grandes empresas. Persistindo a infração, deve ser aplicada multa diária no valor de $\mathrm{R} \$ 50,00$ até a aceitação da obra pelo órgão licenciador ${ }^{[12]}$. Esses valores baixos e a falta de físcalização desestimulam a busca de soluções técnica e ambientalmente adequadas.

A partir dos dados de produção do filme reciclado (Tabela 1), em que é utilizada a máquina de limpeza de plásticos (maior consumidora de água), de, aproximadamente, 90.000 kg/mês; é possível relacionar produção e consumo de água $-90.000 \mathrm{~kg} / 36.000 \mathrm{~L}$ - que resulta em $1 \mathrm{~L}$ de água para realizar a limpeza de $2,5 \mathrm{~kg}$ de plásticos pós-consumo. 


\subsection{Matéria-prima}

A compra de plástico pós-consumo de vendedores autônomos agrega pouco valor social à produção do reciclado. Além disso, não há controle sobre a segurança e higidez da atividade desenvolvida.

A organização de catadores em cooperativas possibilita que os mesmos possam trabalhar em condições mais justas do que quando o fazem isoladamente e, também, oferecer um produto de melhor qualidade. $\mathrm{O}$ incentivo à criação $\mathrm{e}$ ao desenvolvimento de cooperativas ou de outras formas de associação de catadores de materiais reutilizáveis e recicláveis formadas por pessoas físicas de baixa renda é um dos instrumentos da PNRS, que considera a possibilidade do poder público instituir medidas indutoras e linhas de financiamento para implantação de infraestrutura física e aquisição de equipamentos ${ }^{[2]}$.

O contínuo fornecimento de matéria-prima por uma organização adequada de coleta, separação e esquemas de pré-tratamento é uma das quatro condições básicas apontadas por Mader ${ }^{[13]}$ para garantir o sucesso da reciclagem de plásticos. O autor indica também: tecnologia de conversão adequada, mercado para o produto reciclado e viabilidade econômica.

Ainda, a origem do plástico pós-consumo tem implicações econômicas e ambientais. Quanto mais limpa é a matéria-prima adquirida, menor é o consumo de água utilizada na lavagem e maior é a possibilidade de obtenção de resina reciclada de boa qualidade e, consequentemente, do produto final que atenda o desempenho desejado. Por outro lado, a matéria-prima coletada no aterro demanda mais ciclos de lavagem, maior consumo de energia na secagem e tudo isso não é suficiente para garantir um produto final de qualidade. Há situações em que é necessário reprocessar a resina reciclada.

Vale considerar que a matéria-prima virgem é transportada de Camaçari, na Bahia a Teresina, Piauí, cuja distância é cerca de $1.127 \mathrm{~km}$. Já a origem do material pós-consumo é bastante indefinida, mas os vendedores estão concentrados na cidade de Teresina.

\subsection{Energia}

A indústria pesquisada possui vinte e seis máquinas que demandam o uso de energia elétrica. A máquina de limpeza de plásticos é a que apresenta maior consumo de energia em comparação com os demais equipamentos da indústria (cerca de $76 \mathrm{kWh}$ para o processamento de $155 \mathrm{~kg}$ de plásticos).

Apesar da economia de recursos naturais a serem retirados da natureza e a diminuição de materiais com potencial de reutilização e/ou reciclagem enviados para aterros serem as principais justificadas 'ambientais' consideradas na escolha pela reciclagem mecânica, é preciso considerar que as etapas de limpeza e secagem do reciclado não estão presentes no processamento da resina virgem.

Há sempre possibilidade de implantação de uma política interna que objetive a eficiência energética que neste caso em particular, pode iniciar com a aquisição de máquinas que tenha motores mais eficientes, ou seja, devidamente dimensionados para alimentar o sistema de potência a que será exigido.
Silva, Araújo e Moita Neto apresentaram as potências dos equipamentos de uma indústria que desenvolve atividade similar à estudada, neste trabalho, e discutiram a eficiência energética associada às etapas de processamento ${ }^{[14]}$, chegando às mesmas conclusões aqui apresentadas em relação à energia.

\subsection{Condições de higiene de segurança do trabalho}

Conforme o Manual de Saúde e Segurança no Trabalho do Serviço Social da Indústria de São Paulo - SESI/SP ${ }^{[15]}$, os riscos na indústria de transformação do plástico referem-se ao uso das máquinas, disposição inadequada das mesmas, queda devido a óleo ou matéria-prima no piso e incêndio. Os perigos para a saúde dos trabalhadores relacionados são dermatites, inalação de fumos de plástico e perda auditiva por exposição a níveis elevados de ruído.

O mapa de riscos da indústria visitada traz os riscos físicos, químicos, biológicos, aspectos ergonômicos e acidentes (categorias dos riscos ocupacionais) a que estão predispostos os funcionários da indústria de plásticos.

Os agentes classificados na categoria dos riscos físicos são ruído, vibração, umidade, radiações ionizantes e não ionizantes e temperatura extrema (frio ou calor ${ }^{[15]}$. No mapa de riscos da indústria visitada são considerados somente ruído e radiação não ionizada. As fontes de ruído são as extrusoras e, principalmente, a máquina de limpeza de plásticos. A indústria não possui barreiras acústicas e os funcionários ficam expostos durante todo o período de trabalho a elevados níveis de ruído. Os protetores auditivos utilizados são inadequados e não são utilizados regularmente.

$\mathrm{Na}$ categoria de riscos químicos são classificados os agentes que interagem com tecidos humanos provocando alterações na sua estrutura, podendo penetrar no organismo pelo contato com a pele, por ingestão e pela via respiratória nas formas de poeiras, fumos, névoas, neblinas, gases e vapores. Os fatores que determinam o risco são a forma de manipulação dos produtos químicos, a dispersão dos agentes no ambiente de trabalho e o nível de proteção dos trabalhadores ${ }^{[15]}$.

Na indústria visitada, os riscos químicos são associados à utilização do floculante, soda caústica, tinta e solvente no setor de produção de grãos reciclados, para os quais são recomendados o uso de máscara descartável com filtro de exalação, avental plástico e óculos de segurança. No setor de produção de embalagens, é considerado o risco químico associado à geração do pó de polietileno, em que a recomendação é o uso de máscara descartável com filtro de exalação e óculos de segurança. Nos dois setores, verificou-se que os funcionários usam somente a máscara.

A exposição aos riscos biológicos é um dos principais fatores nas indústrias de reciclagem pós-consumo, principalmente, nas etapas de separação, moagem e lavagem do material a ser reciclado e se dá pelas vias cutânea, digestiva e respiratória, podendo causar infecções diversas. As medidas preventivas incluem controle médico, equipamentos de proteção coletiva e individual, higiene no local de trabalho, hábitos de asseio pessoal e vacinação ${ }^{[15]}$.

Os riscos ergonômicos referem-se à adaptação das condições de trabalho às características psicofisiológicas dos trabalhadores e se relacionam diretamente à organização do 
trabalho, ao ambiente laboral e ao trabalhador ${ }^{[15]}$. Na categoria de acidentes são classificados os agentes decorrentes de situações adversas nos ambientes e nos processos de trabalho. $\mathrm{Na}$ indústria pesquisada estão incluídos os riscos de corte, quedas, eletricidade e de incêndio.

Pode-se observar que, na indústria visitada, não há rigidez na observação das Normas Regulamentadoras NR's, tais como: NR-5 (Comissão Interna de Prevenção de Acidentes - CIPA), NR-6 (Equipamentos de Proteção Individual - EPI's), NR-9 (Programa de Prevenção de Riscos Ambientais - PPRA), NR-24 (Condições Sanitárias e de Conforto nos Locais de Trabalho) e NR-25 (Resíduos Industriais). Apesar de haver um mapa de riscos que é de fácil acesso para visualização de todos os funcionários da indústria, as recomendações expressas não são atendidas.

\subsection{Qualidade da sacola}

O plástico reciclado, geralmente, possui propriedades mecânicas inferiores ao material virgem. Tal efeito é contornado, parcialmente, pelo aumento da sua espessura. Logo, enquanto o filme virgem apresenta espessura entre 1,7 e 3,0 $\mu \mathrm{m}$; o filme reciclado tem espessura entre 3,8 e 7,5 $\mu \mathrm{m}$. Além disso, a aparência do reciclado é melhorada com a adição de pigmentos que homogeneízam a cor do filme plástico. Contudo, ainda persiste o odor característico diferente da sacola produzida a partir da resina virgem.

Para Brogaard et al. ${ }^{[16]}$, a qualidade dos produtos resultantes da reciclagem mecânica dos plásticos está relacionada à completa eliminação de contaminantes e à classificação em um único tipo de polímero, que deve ser segregado de acordo com a cor requerida para o seu uso final. Na visão de Shonfield ${ }^{[17]}$, a melhor opção para o gerenciamento de resíduos plásticos misturados, do ponto de vista ambiental, é concentrar-se no desenvolvimento de instalações capazes de fornecer um plástico reciclado de alta qualidade, que possam substituir plásticos virgens. Caso não seja possível ser alcançada esta qualidade, o material deve ser reciclado energeticamente (conversão para combustível) ou para uso como agente redutor em altos-fornos.

Mesmo apresentando uma variedade de possibilidades de aplicações, o plástico reciclado mecanicamente tem limitações de uso, como em embalagens de alimentos pelo risco de haver migração de contaminantes e, consequentemente, comprometimento da segurança alimentar. AAgência Nacional de Vigilância Sanitária (Anvisa) tem regulamentação que proíbe o uso de reciclados na indústria alimentícia. Conforme o item 9 da resolução $n^{\circ} 105 / 99$, somente é autorizado o uso de material virgem para elaboração de embalagens, equipamentos e utensílios em contato com alimentos ${ }^{[18]}$. A exceção é para o poli (tereftalato de etileno) - PET, quando atendidos os requisitos definidos na $\mathrm{RDC} \mathrm{n}^{\mathrm{o}} 20 / 2008^{[19]}$, que contém todos os critérios básicos para a conformidade da segurança e aprovação de embalagens, artigos precursores e PET pós-consumo reciclado grau alimentício (PET-PCR grau alimentício).

A falta de especificidade, mesmo quando é realizada a coleta seletiva, sobre a matéria-prima principal (polietileno) compromete a qualidade do produto final. Por isso, a logística reversa, instrumento da PNRS, é apontada como a solução mais eficaz.

\section{Oportunidades de Melhorias na Indústria de Reciclagem Mecânica de Plásticos}

O atual presidente da Associação Brasileira da Indústria do Plástico (Abiplast), José Ricardo Roriz Coelho,

vê nas deficiências da coleta seletiva e na educação inadequada da população para o correto descarte de materiais passíveis de reaproveitamento o grande gargalo da indústria brasileira de reciclagem ${ }^{[20]}$.

Neste trabalho, foi possível pontuar como essas questões influenciam a sustentabilidade da reciclagem.

Contudo, para todos os problemas encontrados na indústria de reciclagem de plásticos pesquisada pode ser indicado um caminho virtuoso. A mudança da responsabilidade da atividade para cooperativas, com mais possibilidade de desenvolver expertise e, com isso, oferecer produtos de melhor qualidade para a indústria de reciclagem é o primeiro passo para agregar valor social à matéria-prima.

O poder público precisa ter um controle mais rigoroso dos poços e exigir outorga de uso e de lançamento de efluentes em conformidade com a legislação específica. Tais documentos podem condicionar a emissão de alvará de funcionamento da indústria. Esse acompanhamento será um estímulo ao desenvolvimento e adoção de programas de utilização racional da água e de sistemas de tratamento de efluentes. $\mathrm{O}$ aumento de custos resultantes dessas ações será compensado pela ampliação da quantidade de ciclos de reuso da água e pelo atendimento à legislação.

É necessário que os administradores assumam a responsabilidade socioambiental e, assim, conduzam os procedimentos que promovam melhorias ambientais na indústria. Para isso eles precisam estar abertos à inovação por quem mais conhece o processo produtivo. Também, os funcionários precisam se comprometer a utilizar adequada e regularmente os EPI's, manter o ambiente limpo e utilizar racionalmente insumos, água e energia.

Embora a comparação apresentada focalize o processamento dentro da indústria de transformação (portão a portão) entre a resina virgem e a resina reciclada, não se deve esquecer que uma visão ambiental mais abrangente precisa considerar todo o ciclo de vida do produto (berço ao túmulo), podendo, inclusive, modificar as conclusões deste trabalho.

\section{Considerações Finais}

A reciclagem mecânica, tal como realizada nesta pequena indústria de transformação, não é ambientalmente correta e nem socialmente justa, em decorrência de problemas de gestão que refletem negativamente na atividade. Entretanto, diversas iniciativas podem ser tomadas para modificar o quadro apresentado, pois a reciclagem é uma alternativa reconhecida na PNRS.

A lavagem de plásticos pós-consumo introduz um custo econômico e ambiental adicional ao processo pelo consumo de água $(0,4 \mathrm{~L} / \mathrm{kg})$ e energia $(0,49 \mathrm{kWh} / \mathrm{kg})$ demandados nesta etapa. Excetuando-se os impactos à montante da indústria, todos os demais problemas podem ser adequadamente gerenciados na indústria, incluindo o 
tratamento de efluentes, eficiência energética e aquisição de matéria-prima segregada na fonte.

Ao analisar a reciclagem, deve-se considerar particularidades de processamento industrial e de disponibilidade de recursos naturais a fim de apontá-la como a melhor alternativa, pois tais aspectos são determinantes e podem mudar consideravelmente de uma região para outra. Além disso, ressalta-se que o material reciclado não terá as mesmas propriedades e todas as possibilidades de aplicações que tem a resina virgem.

\section{Agradecimentos}

Os autores agradecem ao CNPq pelo financiamento do projeto de pesquisa (471500/2012-7).

\section{Referências}

1. Instituto Brasileiro de Geografia Estatística - IBGE. (2012). Indicadores de desenvolvimento sustentável: Brasil 2012. Rio de Janeiro.

2. Lei $n^{\circ}$ 12.305. (2010, 2 de agosto). Política Nacional dos Resíduos Sólidos. Diário Oficial da União, Brasília.

3. Companhia Ambiental do Estado de São Paulo e Sindicato da Indústria de Material Plástico do Estado de São Paulo CETESB. Sindicato Indústria Material Plástico Estado São Paul-SINDIPLAST. (2011). Guia ambiental da indústria de transformação e reciclagem de materiais plásticos. São Paulo. $91 \mathrm{p}$.

4. Agência Brasileira de Desenvolvimento Industrial-ABDI. (2009). Caracterização da cadeia petroquímica e da transformação de plásticos. São Paulo: Copacabana Consultoria e Treinamento. $285 \mathrm{p}$.

5. Coutinho, F. M. B., Mello, I. L., \& Santa Maria, L. C. (2003). Polietileno: principais tipos, propriedades e aplicações. Polímeros: Ciência e Tecnologia, 13(1), 1-13. http://dx.doi. org/10.1590/S0104-14282003000100005.

6. Spinacé, M. A. S., \& Paoli, M. A. (2005). A tecnologia da reciclagem de polímeros. Quimica Nova, 28(1), 65-72. http:// dx.doi.org/10.1590/S0100-40422005000100014.

7. Bordonalli, A. C. O., \& Mendes, C. G. N. (2009). Reuso de água em indústria de reciclagem de plástico tipo PEAD. Engenharia Sanitária e Ambiental, 14(2), 235-244. http:// dx.doi.org/10.1590/S1413-41522009000200011.

8. Faria, F. P., \& Pacheco, E. B. A. V. (2009). Aplicação da ferramenta produção mais limpa na reciclagem de plástico. In 2nd International Workshop Advances in Cleaner Production (pp. 1-9). São Paulo.

9. Faria, F. P., \& Pacheco, E. B. A. V. (2011). A reciclagem de plástico a partir de conceitos de Produção Mais Limpa. Gestão da Produção, Operações e Sistemas, 6(3), 93-107. Recuperado em 10 de outubro de 2014, de http://revista.feb.unesp.br/index. php/gepros/article/view/534

10. Pacheco, E. B. A. V., Ronchetti, L. M., \& Masanet, E. (2012). An overview of plastic recycling in Rio de Janeiro. Resources, Conservation and Recycling, 60, 140-146. http://dx.doi. org/10.1016/j.resconrec.2011.12.010.

11. Mancini, S. D., Nogueira, A. R., Kagohara, D. A., Schwartzman, J.A. S., Mattos, T., \& Rosa, A. H. (2008). Influência do tipo de coleta (comum ou seletiva) na reciclagem de filmes de poliolefinas pós-consumo. Polímeros: Ciência e Tecnologia, 18(4), 289296. http://dx.doi.org/10.1590/S0104-14282008000400006.

12. Lei $n^{\circ} 4.413$ (2013, 18 de junho). Dispõe sobre os serviços e obras para a coleta, tratamento e disposição final dos esgotos sanitários dos estabelecimentos comerciais, industriais, hospitalares e residenciais no âmbito do município de Teresina. Diário Oficial do Município, Teresina.

13. Mader, F. W. (1992). Plastics waste management in Europe. Macromolecular Symposia, 57(1), 15-31. http://dx.doi. org/10.1002/masy.19920570104.

14. Silva, E. A., Araújo, I. M., \& Moita, J. M., No. (2014). Eficiência energética na indústria de reciclagem e transformação de material plástico. In XII Simpósio Ítalo-Brasileiro de Engenharia Sanitária e Ambiental (pp. 1-8). Natal: ABES.

15. Serviço Social da Indústria - SESI. (2012). Indústria de transformação do material plástico: manual de segurança e saúde no trabalho. São Paulo: SESI-SP Editora. 98 p.

16. Brogaard, L. K., Damgaard, A., Jensen, M. B., Barlaz, M., \& Christensen, T. H. (2014). Evaluation of life cycle inventory data for recycling systems. Resources, Conservation and Recycling, 27, 30-45. http://dx.doi.org/10.1016/j.resconrec.2014.03.011.

17. Shonfield, P. (2008). LCA of management options for mixed waste plastics. Oxon: WRAP. Recuperado em 10 de outubro de 2014, de http://www.wrap.org.uk/sites/files/wrap/LCA $\% 20$ of $\% 20$ Management $\% 20$ Options $\% 20$ for $\% 20$ Mixed $\% 20$ Waste\%20Plastics.pdf

18. Resolução $n^{\circ} 105$, de 19 de maio de 1999. (1999, 19 de maio). Disposições gerais para embalagens e equipamentos plásticos em contato com alimentos. Publicada em 20 de maio de 1999. Diário Oficial da União, Brasília.

19. Resolução RDC no 20, de 26 de março de 2008. (2008, 26 de março). Dispõe sobre o Regulamento Técnico sobre embalagens de poli (tereftalato de etileno) (PET) pós-consumo reciclado grau alimentício (PET-PCR grau alimentício) destinados a entrar em contato com alimentos. Diário Oficial da União, Brasília.

20. Santomauro, A. C. (2014). Reciclagem: escassez de materiais pós-consumo prejudica o desenvolvimento do setor. Plástico Moderno, 480, 18-28.

Enviado: Out. 10, 2014

Revisado: Mar. 24, 2015

Aceito: Jun. 19, 2015 